\title{
IN VITRO INDUCTION OF OCTAPLOID FROM COLCHICINE-TREATED TETRAPLOID PETIOLE EXPLANTS OF PURPLE CONEFLOWER (ECHINACEA PURPUREA L.)
}

\author{
Dahanayake Nilanthi ${ }^{1} *$ and Yue-Sheng Yang ${ }^{2}$ \\ ${ }^{1}$ Department of Agricultural Biology, Faculty of Agriculture, University of Ruhuna, Sri Lanka \\ ${ }^{2}$ Genetic Engineering Laboratory, College of Life Sciences, South China Agricultural University, \\ Guangzhou, 510642, PR China
}

Accepted: $09^{\text {th }}$ April, 2013

Abstract

Petiole explants were obtained from in vitro grown tetraploid $(2 \mathrm{x}=44)$ Echinacea purpurea plantlets. Shoots were regenerated by culturing the explants on MS basal medium containing $0.5 \mathrm{mg} / \mathrm{L}$ benzyladenine $(\mathrm{BA}), 0.01 \mathrm{mg} / \mathrm{L}$ naphthaleneacetic acid (NAA) and four concentrations $(30,60,120$, and $240 \mathrm{mg} / \mathrm{L})$ of colchicine for 30 days, or $120 \mathrm{mg} / \mathrm{L}$ of colchicine for 7, 14, 21 and 28 days. The regenerated shoots were induced to root on MS basal medium with $0.01 \mathrm{mg} / \mathrm{L} \mathrm{NAA}$, and then the root-tips of the regenerated shoots were sampled for count of chromosome number. It was found that a treatment duration of $>7$ days was necessary for induction of octaploids $(8 \mathrm{x}=88)$ shoots, and treatment with $120 \mathrm{mg} / \mathrm{L}$ colchicine for 28 days was the most efficient for the induction of octaploids, yielding $10 \%$ of octaploids among all the regenerated shoots. Chimeras were observed in almost all the treatments. However, the ratio of octaploid to tetraploid cells in a chimeric plant was usually low. In comparison with tetraploid plants, octaploid plants in vitro had larger stomata and thicker roots and had prominently stunt plant with very short life cycle. Octaploid $E$. purpurea plantlets can't survival in the natural environment.

Key words: Chimera, Chromosome, Purple coneflower, Octaploid, Tissue culture

\section{INTRODUCTION}

Echinacea purpurae L, (Purple coneflower), is one of the most popular herbs with a long history of medicinal use for a wide variety of illnesses, such as syphilis, septic wounds, snakebites, blood poisoning, common cold, influenza, and other upper respiratory tract infections (Hobbs 1994, Melchart et al. 2004). The chemistry of Echinacea species has been well documented, and several groups of components, including alkamides, caffeic acid derivatives, and polysaccharides are considered important for activity (Barnes et al. 2005). In the recent years, global demand for products of purple coneflower has increased steadily due to the frequent occurring of threatening pandemic diseases caused by viruses. Under this background, biotechnological researches on mass propagation and genetic improvement of this crop have been conducted (Mechanda et al. 2003; Wu et al. 2007).

Polyploids, in spite of low seed-setting or sterility, are usually superior to diploids with re-

\footnotetext{
*Corresponding author: nilanthi@agbio.ruh.ac.lk
}

spect to genetic adaptability and tolerant to environmental stress (Lewis 1980). Hence, polyploids of purple coneflower are more valuable as they contain higher biomass and functional compounds than the diploids (Gao et al. 1996). Induction of polyploidy has become one of the strategies for crop improvement. Out of many applicable methods, the application of colchicine to double the chromosome numbers has been adopted successfully in many plant species (Luckett 1989, Clarindo et al. 2010). Purple coneflower has been confirmed to be a diploid with a chromosome number of in somatic cell (McGregor 1968). However, chromosome doubling has not yet been achieved in purple coneflower.

After successful regeneration of haploid plants through anther culture in purple coneflower for the first time ( $\mathrm{Wu}$ et al. 2007), we focused on doubling the chromosome number of diploid, tetraploid and haploid plant. In this paper, details of regeneration of the octaploid plants by treating tetraploid petiole explants with colchicine are reported. 


\section{MATERIALS AND METHODS}

Plant Source: Seeds of purple coneflower were purchased in a supermarket produced by the Company of Plantation Products (Norton, MA, USA), and plants were grown at the Garden of Chinese Medicinal Plants on the campus of South China Agricultural University. Seeds were collected from these seed-grown plants and used for the present studies.

Establishment of Aseptic Seedlings and Preparation of Petiole Explants: Seeds were surface sterilized by immersing in $70 \%$ ethanol for 1 minutes and soaking in a $0.1 \%$ mercuric chloride solution for 10 minutes followed by $1 \%$ sodium hypochlorite solution containing one drop of Tween 20 per $50 \mathrm{~mL}$ for $10 \mathrm{~min}-$ utes. Surface-sterilized seeds were then rinsed three times in sterile deionized water and inoculated to a medium comprised of halfstrength MS salts, $1 \%$ sucrose and $500 \mathrm{mg} / \mathrm{L}$ lactalbumin hydrolysis and the medium was solidified with $0.2 \%$ Phytagel prior to autoclaving. After 14 days in dim light for germination, the resulted seedlings were transferred to a medium containing full-strength MS salt, $1 \%$ sucrose, and gelled with $0.2 \%$ Phytagel for further growth. Petioles of about two-month old seedlings were cut into $7-10 \mathrm{~mm}$ long segments and used as explants.

Preparation of Media: Each bottle was filled with $40 \mathrm{~mL}$ medium and covered with an airtightly polycarbonate screwed cap. Shoot regeneration medium for culture of petiole explants comprised of MS salts, 3\% sucrose, $0.5 \mathrm{mg} / \mathrm{L}$ BA, $0.01 \mathrm{mg} / \mathrm{L}$ NAA, and rooting medium of the regenerated shoots comprised of MS salts, $3 \%$ sucrose, $0.01 \mathrm{mg} / \mathrm{L}$ NAA. All the media used were adjusted to a $\mathrm{pH}$ value of with $1 \mathrm{~N} \mathrm{NaOH}$ or $1 \mathrm{~N} \mathrm{HCl}$ solution, and gelled with $0.6 \%$ agar prior to autoclaving at pressure of $1.4 \mathrm{~kg} \mathrm{~cm}^{-2}$ for 20 minutes. When colchicine was used, it was dissolved in distilled water to a concentration of $5 \mathrm{mg} / \mathrm{mL}$, filtered sterilized and then added to warm (about $70^{\circ} \mathrm{C}$ ) autoclaved media.
Induction of Chromosome Doubling: Petiole explants were pre-cultured on shoot regeneration medium for one week to heal the cutting wound and initiate cell division, and then transferred to shoot regeneration medium with different concentrations $(0,30,60,120,240 \mathrm{mg} / \mathrm{L})$ of colchicine for 30 days or with $120 \mathrm{mg} / \mathrm{L}$ colchicine for different durations $(7,14,21,28$ days). Eight explants were cultured in one bottle.

Shoot Regeneration and Rooting of the Regenerated Shoots: After the colchicine treatment, the treated explants were transferred to the shoot regeneration medium and cultured for 40 days. The regenerated shoots were cut from the mother tissues and cultured to the rooting medium for the initiation of roots and further growth of the intact regenerated plantlets.

Maintenance of Cultures: Except seed germination culture which was kept under dim light, all the other cultures were kept in lighted conditions with a 12-hour photoperiod under coolwhite light (about $50 \mathrm{~mol}$ ), and all the cultures were kept in a room with temperature of $25-27^{\circ} \mathrm{C}$.

Observation of Chromosomes and Determination of Ploidy Level: Fifty one regenerated plants were randomly selected and from each plant all actively growing root tips of $5-10 \mathrm{~mm}$ in length were excised. These root tips were treated with $0.1 \%$ colchicine water solution at room temperature for 4 hours, washed with tap water and transferred to Carnoy's solution for fixing at least 24 hours at room temperature. The fixed root tips were then hydrolyzed in $1 \mathrm{~N}$ $\mathrm{HCl}$ for $10-15$ minutes at $65^{\circ} \mathrm{C}$. After hydrolysis, root tips were rinsed with tap water for 10 minutes and cut into shorter root tips of 1.5 $\mathrm{mm}$ in length. These prepared root tips were then placed on slide glass, stained with one drop of carbol fuchsin solution for 1-2 minutes, squashed under cover glass and observed for chromosome numbers under a microscope (Leica DLMB2) through a 60 object lens, and photos were taken with the associated appara- 
tus (Gao et al 1996). A plant with all the root tip cells showing 22 chromosomes was determined as diploid, with some cells showing 22 and the other cells showing 44 chromosomes was determined as chimera, and with all the cells showing 44 chromosomes was determined as tetraploid. For confirmation of the nonchimeric condition of the tetraploid plants that had been determined by chromosome counting of the root tip cells, shoot tips were sampled from five plants of which all the root tip cells had 44 chromosomes and prepared by the same method shown above and the chromosomes of the shoot meristem cells were counted.

Stomata Analysis: For stomata analysis, a few pieces of epidermal layer were torn from the abaxial side of relatively mature leaves (leaf no. 4 or 5 from the top of the shoot) of tetraploid, diploid and chimeric plants. These epidermal layers were then mounted on slide glass with one drop of distilled water and a piece of cover glass for measuring stomata sizes under the above mentioned microscope with an associated computer.

Data Analysis: All the experiments were arranged in Randomized Complete Block Design (RCBD). Statistical analysis was carried out using the student Newman-Kuells means separation test of SAS (SAS Institute, Cary, NC, 1995). Significance of differences among means was determined by Duncan's multiple range testes at $\leq 5 \%$ level.

\section{RESULTS}

Influence of Concentration of Colchicine on Shoot Regeneration: Shoot regeneration from petiole explants generally took place after one month of culture on regeneration medium, and the regenerated shoots could continue grow on the same medium for another 10 days without declining in vitality. Colchicine added in the medium significantly inhibited shoot regeneration; the higher was concentration of colchicine, the lower regenera- tion rate (Table 1). Colchicine also delayed the regeneration progress and induced obviously more callus on the cutting surface of the explants.

Table 1: Effect of colchicine concentration on shoot regeneration from petiole explants. Data were collected after 30 days on regeneration medium containing colchicine and 40 days on colchicine-free regeneration medium except for the control, data for which were collected after 40 days of culture without transfer to new medium.

\begin{tabular}{lll}
\hline $\begin{array}{l}\text { Colchicine concen- \% } \\
\text { tration }(\mathrm{mg} / \mathrm{L})\end{array}$ & $\begin{array}{l}\text { Shoot } \\
\text { tion }\end{array}$ & $\begin{array}{c}\text { regenera-No. shoots per } \\
\text { bottle }\end{array}$ \\
\hline $0($ control $)$ & $82.9 \mathrm{a}^{*}$ & $13.7 \mathrm{a}$ \\
30 & $57.3 \mathrm{~b}$ & $5.2 \mathrm{~b}$ \\
60 & $42.5 \mathrm{c}$ & $4.3 \mathrm{c}$ \\
120 & $17.0 \mathrm{~d}$ & $1.7 \mathrm{c}$ \\
240 & $6.3 \mathrm{e}$ & $0.6 \mathrm{~d}$ \\
\hline
\end{tabular}

*Data in the same column followed by different letters are significantly different by Duncan't test at $\leq 5 \%$ level.

Effect of Colchicine Concentration on Chromosome Doubling: Explants were treated with various concentrations of colchicine for 30 days. Effect of colchicine on chromosome doubling was evaluated by counting the chromosome numbers in the root tip cells of the plants regenerated from the colchicine treated petioles. Figure 1 shows root-tip cells and chromosomes of octaploid plantlets regenerated after colchicine treatment. Chromosome counting of shoot meristem cells confirmed further the non-chimeric status of these octaploid plants.

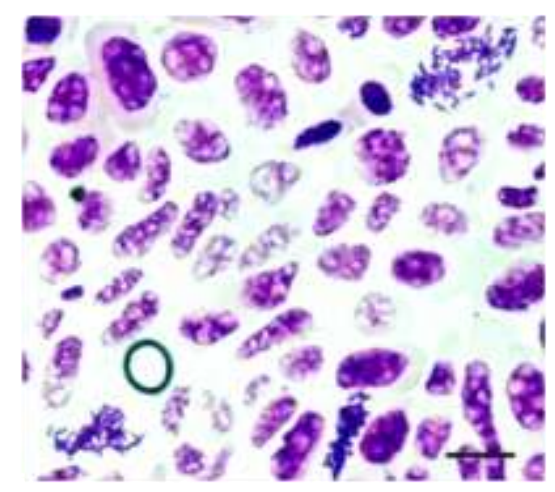

Figure 1: Chromosome in root tip cells of octaploid plantlets $(2 \mathrm{x}=88)$. Bar $=40 \mathrm{~m}$. 
The effect of colchicine concentration on doubling chromosome number was summarized in Table 2. It is indicated that $30 \mathrm{mg} / \mathrm{L}$ was not very effective because no octaploid plants but chimera plants were induced. $120 \mathrm{mg} / \mathrm{L}$ colchicine in the medium exhibited the best doubling effect, among 10 plantlets examined, chromosomes in 1 plantlet was confirmed to have been completely doubled. Colchicine at concentrations of 60 and $240 \mathrm{mg} / \mathrm{L}$ was also effective, being able to induce chromosome doubling and form chimeras but was not as effective as at concentration of $120 \mathrm{mg} / \mathrm{L}$.

\section{Effect of Treatment Duration of Colchicine} on Chromosome Doubling: In the abovedescribed experiments, $120 \mathrm{mg} / \mathrm{L}$ colchicine treatment induced chromosome doubling with the highest efficiency. In this experiment, explants were inoculated on media supplemented with $120 \mathrm{mg} / \mathrm{L}$ colchicine for various durations. The data in Table 3 showed that longer duration of colchicines. Table 3: Com-

Table 2: Comparison of the effect of colchicine concentration on chromosome doubling of 10 regenerated plants

Colchicine con- No. of plants with indicated centration $(\mathrm{mg} / \mathrm{L})$ _ chromosomes

\begin{tabular}{|c|c|c|c|}
\hline & \multicolumn{3}{|c|}{$4 \mathrm{x}$ plants $8 \mathrm{x}$ plants Chimeras } \\
\hline 30 & 6 & 0 & 4 \\
\hline 60 & 5 & 0 & 5 \\
\hline 120 & 3 & 1 & 6 \\
\hline 240 & 4 & 0 & 6 \\
\hline
\end{tabular}

Table 3: Comparison of the effect of treatment duration on chromosome doubling of 10 regenerated plants.

Treatment du- \% shoot regen- No. shoots per ration (days) eration $\quad$ bottle

\begin{tabular}{lll}
\hline 7 & $61.4 \mathrm{a}^{*}$ & $5.9 \mathrm{a}$ \\
14 & $51.1 \mathrm{~b}$ & $4.2 \mathrm{~b}$ \\
21 & $40.0 \mathrm{c}$ & $3.1 \mathrm{c}$ \\
28 & $14.5 \mathrm{~d}$ & $1.0 \mathrm{~d}$ \\
\hline
\end{tabular}

*Data in the same column followed by different letters are significantly different by Duncan't test at $\leq 5 \%$ level. parison of the effect of duration of $120 \mathrm{mg} / \mathrm{L}$ colchicine treatment on shoot regeneration from petiole explants. Data were collected 40 days after transfer of the colchicine treated explants to colchicine-free regeneration medium.

Roots were sampled from plantlets growing from the 10 regenerated shoots and chromosome number of the root-tip cells was counted. Result of chromosome counting is summarized in Table 4. The highest percentage $(10 \%)$ of octaploid induction occurred on the regeneration medium treated with $120 \mathrm{mg} /$ $\mathrm{L}$ colchicine for 28 days. However, 21-day treated explants also generated a substantial number of octaploids whereas no octaploids were observed in 7-day and 14- day treatments.

Table 4: Comparison of the effect of colchicine treatment duration on chromosome doubling of 10 regenerated plants.

\begin{tabular}{llll}
\hline $\begin{array}{l}\text { Treatment } \begin{array}{l}\text { duration } \\
\text { days) }\end{array} \\
\text { nyyyy}\end{array}$ & \multicolumn{2}{l}{$\begin{array}{l}\text { No. each kind of plants on the } \\
\text { base of chromosome counting }\end{array}$} \\
\cline { 2 - 4 } & $4 x$ plants & 8 x plants & Chimera \\
\hline 7 & 4 & 0 & 6 \\
14 & 3 & 0 & 7 \\
21 & 4 & 1 & 5 \\
28 & 3 & 1 & 6 \\
\hline
\end{tabular}

Table 5: Comparison of stomata size between diploid and tetraploid plantlets

\begin{tabular}{lll}
\hline $\begin{array}{l}\text { Ploidy level } \\
\text { of plant }\end{array}$ & $\begin{array}{l}\text { Stomata } \\
\text { length }(\mathrm{m})\end{array}$ & $\begin{array}{l}\text { Stomata } \\
\text { width }(\mathrm{m})\end{array}$ \\
\hline Tetraploid & $144.810 \mathrm{a}^{*}$ & $111.758 \mathrm{a}$ \\
Octaploid & $165.743 \mathrm{~b}$ & $126.361 \mathrm{~b}$ \\
\hline
\end{tabular}

*Data in the same column followed by different letters are significantly different by Duncan't test at $\leq 5 \%$ level. 


\begin{abstract}
Morphological Difference among Diploid, Tetraploid and Chimeric Plantlets: Sizes of stomata on leaves varied largely even among those of the same leaf, but statistically significant mean size difference could still be detected between tetraploid and octaploid (Table $5)$. The obviously bigger mean size of octaploid than tetraploid stomata suggests bigger cells in plants octaploid than in tetraploid plants.
\end{abstract}

There were no noticeable morphological differences in shape of the stomata among the three kinds of plants, however, on a piece of leaf epidermal layer of a chimeric plant, some areas were situated with more number of larger size stomata which are very likely octaploid and some areas were situated with more number of smaller size stomata which are very likely tetraploid.

Morphological difference in root system between in vitro tetraploid and octaploid plantlets was significant. In comparison with tetraploid plants, octaploid plants in vitro had larger stomata and thicker roots and had prominently stunt plant with very short life cycle. Octaploid Echinacea purpurea plantlets can't survival in the natural environment. Morphology of chimeric plants with higher tetraploid to octaploid cell ratios was more similar to tetraploid plants than those with lower tetraploid to octaploid cell ratios.

Octaploid Echinacea purpurea plantlets survival in the natural environment even one day. All plantlets were died within few days in culture tubes with MS basal medium. They were prominently stunt plant with very short life cycle.

\section{DISCUSSION}

In preliminary experiments of the present study, various colchicine concentrations (from 100 to $1000 \mathrm{mg} / \mathrm{L}$ ) associated with short duration (one to five days) treatments, as methods of in vitro chromosome doubling frequently reported (Song et al. 1997; Thao et al. 2003), were found not effective. No tetraploid but only chimeric plants were produced in these experiments (data not shown). On the bases of the preliminary experimental results, we tried to treat the plant material with colchicine for longer duration.

In comparison with short duration of high colchicine concentration treatments, long duration treatments of colchicine were much less attempted. Chakraborti et al. (1998) treated mulberry with $1000 \mathrm{mg} / \mathrm{L}$ colchicine for one day and 28 days and obtained equally good results (Chakraborti et al. 2003). However, Portela de Carvalho et al. treated annatto with 25, 250 and $1250 \mathrm{M}$ (about 10, 100 and 500 $\mathrm{mg} / \mathrm{L}$ resp.,) colchicine for 15 and 30 days obtained only one tetraploid shoots in the treatment of $25 \mathrm{M}$ colchicine for 15 days (Carvalho et al. 2005). In the present study, we found that colchicine at $120 \mathrm{mg} / \mathrm{L}$ was suitable for induction of chromosome doubling in purple coneflower, and a certain long duration (longer than seven days) of colchicine treatment was necessary for obtaining completely doubled chromosome tetraploid plantlets from diploid explants, with longer duration the better among the four durations tested.

Chimeric plants were frequently produced in the experiments. However the production of chimeras was of much less value in agricultural production in comparison with tetraploid or octaploid plants. Although there have been many methods for clarifying ploidy level of plants (Thao et al. 2003; Carvalho et al. 2005; Borrino et al. 1988; Gu et al. 2005), all these methods require certain and even sophisticated techniques. Simple methods for early identification of ploidy level in regenerated plants have important application value, especially when a large amount of regenerated plants are to be identified. In a previous report on regeneration of haploid from anther cultures of purple coneflower, we found that the haploid plantlets have evidently thinner roots than those of diploid ones. In the present 
study, obvious difference in root morphology between diploid and tetraploid were also observed. The finding of the difference in root morphology between plants of different ploidy levels can serve as a convenient and reliable method for identifying plants of certain ploidy level from the others in purple coneflower, and may probably be applicable to other plant species as well.

\section{CONCLUSION}

Treating the petiole explants with $120 \mathrm{mg} / \mathrm{l}$ colchicine for 30 days found to the most efficient treatment for the induction of Octaploids in Echinacea purpurae L, (Purple coneflower).

\section{REFERENCES}

Barnes J, Anderson LA, Gibbons S and Phillipson JD 2005 "Echinacea species (Echinacea angustifolia (DC.) Hell., Echinacea pallida (Nutt.) Nutt., Echinacea purpurea (L.) Moench): a review of their chemistry, pharmacology and clinical properties," Journal of Pharmacy and Pharmacology, 57(8): 929-954.

Borrino EM and Powell W 1988 Stomata guard cell length as an indicator of ploidy in microspore-derived plants of barley," Genome, 30:158-160.

Chakraborti SP, Vijayan K, Roy BN and Quari SMH 1998. "In vitro induction of tetraploidi mulberry," Plant Cell Reports, 17: 799-803.

Carvalho JFRP de, Carvalho CR de and Otoni WC 2005 "In vitro induction of polyploidy in annatto (Bixa orellana)," Plant Cell, Tssue and Organ Culture, 80(1): 69-75.

Clarindo WR, Roberto de Carvalho C, Araujo FS, Santiago de Abreu I and Otoni WC 2008. Recovering polyploidy papaya in vitro regenerants as screened by flow cytometry," Plant Cell, Tissue and Organ Culture, 92: 207-214.

Gao SL, Zhu DN, Cai ZH and Xu DR 1996 "Autotetraploid plants from colchicinetreated bud culture of Salvia miltiorrhiza Bge," Plant Cell, Tissue and Organ Cul- ture, 47(1): 73-77.

Gu XF, Yang AF, Meng Hand Zhang JR 2005 "In vitro induction of tetraploid plants from diploid Zizyphus jujuba Mill. cv. Zhanhua," Plant Cell Reports, 24(11): 671676.

Hobbs C 1994. "Echinacea. A literature review," Herbal Gram, 30: 33-47.

Lewis WH and Ploidy 1980. Biological Relevance, Plenum, New York, NY, USA.

Luckett DJ 1989. "Colchicine mutagenesis is associated with substantial heritable variation in cotton," Euphytica 42(1-2): 177182.

Melchart D, Linde K, Fischer P and Kaesmayr J 2004. "Echinacea for preventing and treating the common cold (Cochrane review)," in The Cochrane Library, Update Software, Oxford, UK.

Mechanda SM, Baum BR, Johnson DA and Arnason JT 2003 Direct shoot regeneration from leaf segments of mature plants of Echinacea purpurea (L.) Moench. In Vitro Cellular and evelopmental Biology Plant. 39 (5): 505-509.

McGregor RL 1968. "The taxonomy of the genus Echinacea (Compositae)," University of Kansas Science Bulletin, 48(4): 113-142.

Song P, Kang W and Peffley EB 1997 "Chromosome doubling of Allium fistulosum $\mathrm{x}$ A. cepa interspecific F1 hybrids through colchicine treatment of regenerating callus," Euphytica. 93(3): 257-262.

Thao NTP, Ureshino K, Miyajima I, Ozaki Y and Okubo H 2003 "Induction of tetraploids in ornamental Alocasia through colchicine and oryzalin treatments," Plant Cell, Tissue and Organ Culture, 72(1): 19-25.

Wu CH, Murthy HN, Hahn EJ and Paek KY 2007 "Large-scale cultivation of adventitious roots of Echinacea purpurea in airlift bioreactors for the production of chichoric acid, chlorogenic acid and caftaric acid," Biotechnology Letters, 29(8): 1179-1182.

Zhao FC, Nilanthi D, Yang YS and Wu H 2006 "Anther culture and haploid plant regeneration in purple coneflower (Echinacea purpurea L.)," Plant Cell, Tissue and Organ Culture 86(1): 55-62. 